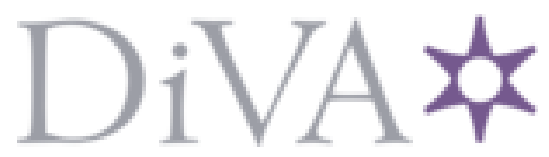

http://www.diva-portal.org

This is the published version of a paper presented at Electric Vehicle Conference (IEVC), 2014 IEEE International.

Citation for the original published paper:

Chen, F., Kringos, N. (2014)

Towards new infrastructure materials for on-the-road charging: A study of potential materials, construction and maintenance.

In:

INSPEC Accession Number

http://dx.doi.org/10.1109/IEVC.2014.7056235

N.B. When citing this work, cite the original published paper.

Permanent link to this version:

http://urn.kb.se/resolve?urn=urn:nbn:se:kth:diva-163717 


\title{
Towards new infrastructure materials for on-the-road charging
}

\author{
A study of potential materials, construction and maintenance
}

\author{
Feng Chen, and Nicole Kringos \\ Transport Science Department \\ KTH Royal Institute of Technology \\ Stockholm, Sweden \\ E-mail: feng.chen@abe.kth.se, nicole.kringos@abe.kth.se
}

\begin{abstract}
As a future-oriented industry, the electrified mobility has the potential to enhance the sustainability of our road transportation sector radically. With the aim to break the EV batteries' bottleneck (e.g., cost, range anxiety, long waiting time) by focusing not on the battery but on the solution to charge it conveniently, different on-the-road-charging solutions have been found under active investigation. From a road infrastructure perspective, however, little attention has been given to the practical, physical roads where these charging solutions will be enabled. In reality, good performance of E-Road infrastructure in aspects such as robustness, durability, costeffectiveness will be crucial for the final success. Taking the Inductive Power Transfer (IPT) charging solution in a dynamic way as a basis, this paper mainly discusses about the physical infrastructural aspect i.e. the road infrastructural materials and the changed construction and maintenance principles. The paper aims to give developers in this field more awareness of the necessity and potential cross-coupling benefits from interdisciplinary collaboration, by taking the road infrastructure research into the concept development of E-Roads.
\end{abstract}

Keywords - electric vehicle; inductive charging; infrastructure materials; construction; maintenance

\section{INTRODUCTION}

It is well-known that the road electrification infrastructure has the potential to promote the sustainability of our road transportation sector significantly in the long term run. The electrification of road transportation, in reality, already started long ago by the electrically powered public transportation vehicles i.e. the trolleybuses that receiving electrical power from overhead electrical cables through a pantograph. The original prototype of the trolleybus dates back to the rail-less 'Electromote' which was presented to the public in Halensee, Berlin in 1882 [1]. The development and operations of trolleybuses has been found throughout the last century but unfortunately went out of fashion towards the end. It was concluded in [2] that passengers liked its quiet, vibration-free operation, high performance and overload capacity; operators welcomed its long life and low maintenance requirements. However, the operational inflexibility restrains such as being tied to fixed routes, made trolleybuses difficult to integrate with motor buses. Besides that, the proliferation of road

This work was supported by the European Commission under FABRIC, a collaborative project part of the FP7 for research, technological development and demonstration. improvement schemes, and high cost of the overhead lines and energy finally lead to their demise. An alternative aiming to improve the operational inflexibility of trolleybus was found in the transfer of this physical contact between the vehicle and electrical power from the overhead to the road surface. This contact can be served as a "collector" from electric power rails located in the slot of a conduit below the roadway, an example of which is given in the patent in [3]. It can also be the contact between the vehicle and the conductive 'strip' mounted on the road surface, like the 'power take-off system' in [4] or the mechanical pantograph 'brush' in the "E-TRAN" concept in [5]. However, electrical safety issue, reliability and cost have restrained the application of these technologies. The second method to power road vehicles was found in the employment of a battery pack to store the electrical energy and replenish it for EV's power supply when needed. The idea to power vehicle by a battery dates back to the early test performed by Robert Davidson in 1842 [6]. He ran a locomotive with a small battery on the Edinburgh \& Glasgow Railway, achieving a maximum speed of 4 miles per hour. Noting that our predecessors were just trying to find a suitable automobile propulsion method, less attention was paid for electric propulsion after the advent of the internal combustion engine.

In recent decades, due to the concern over our societies' sustainability development, the battery solution was paid attention again since it is green and renewable. The high cost, range anxiety and long waiting time, however, still restrain their application potential. Therefore, expectation has been found given to the development of the appropriate On-the-road charging infrastructure that allowing recharging the battery timely. In this sense, the idea behind the On-the-road charging infrastructure is to focus on not the EVs' battery but the technologies that allow for recharging it conveniently. In this paper, the On-the-road charging infrastructure or can be easier called 'Electrified-Road' (E-Road) infrastructure is defined as a transportation infrastructure that is able to "deliver the electrical power to charge the EV efficiently stationary or even in motion, using specific conductive or contactless charging systems". Within this definition, the E-Road can serve as an ordinary road for vehicles driving on and at the same time delivering electrical energy to power EVs (refer in particular to the EVs that use batteries). In this sense, the charging system is 
the functional component that will be enabled from the road matrix. Currently, two charging methods in both stationary and dynamic ways have been found developed towards the application: i) Conductive Charging. Stationary conductive charging way is to use a cable to plug into a car by hand and has been commonly seen in existing EV charging infrastructures. For dynamic conductive charging, different connection modes have been found, e.g., overhead pantograph and conductive track that mounted on the road surface. ii) Contactless Charging. This solution uses a Wireless Power Transmission (WPT) system to deliver electrical energy to the EV at a gap distance stationary or dynamically. The contactless charging solution was developed later than conductive solution but indicates convenient and possible safer characteristics, so as to be regarded as an ultimate solution. Being a near-field WPT technology, the Inductive Power Transfer (IPT) charging technology has shown good performance and is being studied actively as a contactless charging solution, which is therefor given as the technical base in this paper.

Many different disciplines are currently pursuing the development of knowledge and technology that will be needed to enable the electrification of road transportation. Compared to the active studies over the different charging solutions, safety issues, power grid and cost, little attention has been yet given to the practical, physical roads where these charging solutions will be enabled. This paper thus attempts to address important missing interfaces from a road infrastructure point of view, which mainly consists of two parts: 1) A survey over the existing E-Road test sites, based on which the challenges of practical, physical infrastructural aspect are focused; 2) Discussions are performed over the potential to ensure the ERoad's good functionality in a very long service time by using appropriate infrastructural materials. This paper aims to give developers in this field more awareness of the necessity and potential cross-coupling benefits from interdisciplinary collaboration, by taking the road infrastructure research into the concept development of E-Roads.

\section{A SURVEY ON THE E-ROAD PILOT STUDIES}

The authors in [7] have already pointed out the problem areas to be solved for IPT solution are the development of appropriate roadway infrastructure, e.g., the fragile ferrite materials have to be integrated into the road pavement to give a long service life in a very hostile environment (considering the mechanical and environmental loading). Systematic pilot study of IPT charging system can be found dating back to the project organized by California Partners for Advanced Transit and Highways (PATH) in the period of 1980s 1990s [8]. The cross section geometry of the IPT charging roadway is shown in Fig. 1. In this, an epoxy/sand/fiberglass approach was employed to fabricate the inductor modules, which were embedded into the pavement as entirety. It was reported that mechanical integrity problems were immediately induced after the construction. During the installation of conductors, they attempted to seal the conductor slots with clay but the clay entered the vaults. In many locations, the seal was inadequate because the polyester leaked through the seal into the vault, leaving sand with a thin film of polyester coating the individual grains and air-rather than polyester-filling the remaining volume. Hence, these areas were very weak and cracks developed shortly after being exposed to traffic. Polyester rather than epoxy as the resin mixed with sand was used for potting the conductors in place; thus, the polyester and aluminum in the slot expand much upon heating (primarily solar loading), causing cracking along both edges of the conductor slots. Furthermore, due to the thermal expansion discontinuities around the potting compounds, the cables buckled seriously and caused the most severe failure of the mechanical integrity of the roadway.

Recently, several on-going dynamic IPT charging test sites have been found under active investigation. However, most of their focuses were given to the feasibility assessment of the charging systems while rare studies on the infrastructural aspect are available. The collected information regarding their construction is described as follow.

a) KAIST'S OLEV project (in South Korean, [9]): The existing road lane was firstly excavated, and then the cable conductors and ferrite cores were installed. These conductors and ferrite cores were sealed by cement concrete then and a thin asphalt overlay was applied finally. In this, no inductor module were used when compared to the PATH's way.

b) Flanders' DRIVE project (in Belgium, [10]): The total test track length is 600 meters, which include two inductive sections. In this, section 1 used the cement concrete pavement and section 2 used the asphalt concrete pavement. They claimed that it is possible to integrate the system into both concrete and asphalt road surface but tolerances hint towards prefabricated modules.

c) Slide-in Electric Road System-Inductive project (in Sweden, [11]): The test track facility has got a total length of $300 \mathrm{~m}$ of which 4 highway segments of $20 \mathrm{~m}$ have been built. Firstly, the top $200 \mathrm{~mm}$ of asphalt road surface were ground away in a strip $800 \mathrm{~mm}$ wide. Then, the $20 \mathrm{~m}$ primary winding segments are installed in a carrier to maintain the winding shape, while the carrier is fixed to the roadbed and the cable ends routed to the wayside power converter. Finally, $40 \mathrm{~mm}$ asphalt is applied to complete the segments installation. One must notice that ferrite core is not used in this pilot.

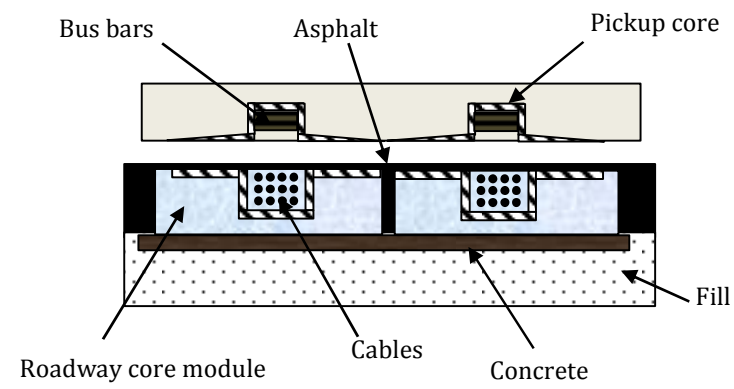

Fig. 1. Illustration of roadway and pickup inductor cross section geometry

\section{NEW INFRASTRUCTURAL MATERIALS FOR E-ROAD INFRASTRUCTURE}

It can be seen from the survey that the infrastructural aspect of the E-Road can be of great importance. However, little practical research has been reported in terms of the protection 
of the fragile IPT facilities and also the corresponding road structure. For a normal road pavement, both asphalt and concrete materials are used currently. Asphalt pavements are found to be comfortable, fast in construction and easy in maintenance, having good skid resistance, and the materials are almost $100 \%$ recyclable. On the other hand, concrete pavements have higher strength, are sometimes more durable and need fewer repairs. In the case of the E-Road, it is unlikely possible to adopt the traditional construction and maintenance principles (asphalt or concrete) directly, and several modifications are needed in accordance with the geometry and mechanical characteristics of the IPT systems. In the following the potential infrastructural materials that may contribute to the E-Road performance in the long term run are discussed, towards the good structural integrity, cost-effective maintenance, and lowest impact on the IPT charging system.

\section{A. Consideration over the structural integrity}

Due to the structural and material deteriorations caused by the traffic and environmental loading, distresses in the form like cracking and rutting can develop gradually during a road's service lifetime. Theories and models are available to predict these distresses in current pavement design framework, however, their implementation for composite road structures can be perceived as difficult. A good example is the reflective cracking failure for the Hot Asphalt Mix (HMA) overlay that placed over the existing Portland Cement Concrete (PCC) pavement. In this, the cracking mechanisms for HMA overlay structure under traffic and environmental loading is shown in Fig. 2, which are very complex for analysis. Similarly, given the presence of the charging facilities, unexpected deformations or cracks can be induced inside E-Road structure as a result of the traffic and environmental loading. The immediate impact is that the E-Road structure will experience premature damages in early lifetime, and the malfunction of the whole infrastructure can be the result.
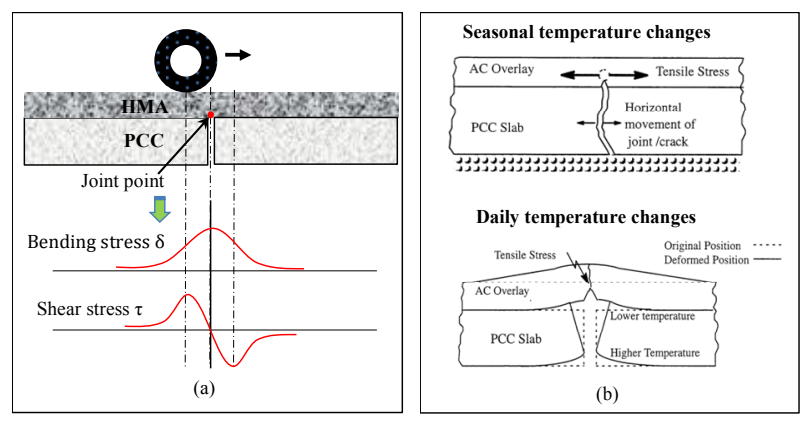

Fig. 2. Schematic of reflective cracking mechanisms due to (a) traffic loading and (b) temperature variations (after Lytton [12], and Mukhtar et al. [13])

According to the studies in [14-18], circular shape structures have been studied actively as the layout of charging transmitter in stationary IPT systems, while newly polarized and double polarized structures suggest better tolerance for gap distance and misalignments. For a dynamic off-board IPT system, the geometry can be the successive placement of the above monomers, while long or sectioned wire-loops structure and ultra slim bone structure have also been found used [1923]. At this early development stage, however, there is no standard or guideline available regarding the IPT systems' geometry design and materials' properties.

In this paper, the charging facilities are assumed to be integrated into the existing pavement as an entirety and the main attention is thus given to the performance of this 'composite road' under traffic and environmental loading. A schematic illustration of a potential E-Road structure that based on upgrading existing road pavement is shown in Fig. 3. In this, an extra thin protection overlay (asphalt/concrete) on the Eroad surface can be very useful, which has already been seen in the existing pilots. The potential benefits can be expected by this consideration include: 1) the IPT facilities can be protected against accidental or environmental loading damage, and also water ingress corrosion; 2) an overlay may act as a stress relief layer to improve structural integration and benefit the E-road's long term performance; 3 ) The maintenance and rehabilitation actions will be confined to only the overlay, which can be very cost-effective; 4) The safety issues relating to high voltage IPT system can be avoided. However, an additional overlay will increase the energy transfer distance $(2-5 \mathrm{~cm})$, so should be as thin as possible. In addition, the IPT embedment is better done in the pavement surface layer rather than the structural layer. The reason for this is that the protection of the structural layer is a very important aspect for the road pavement design, while the failure of which will cause expensive rehabilitation or reconstruction actions. Of course, this consideration will depend much on the geometry and mechanical properties of charging facilities.

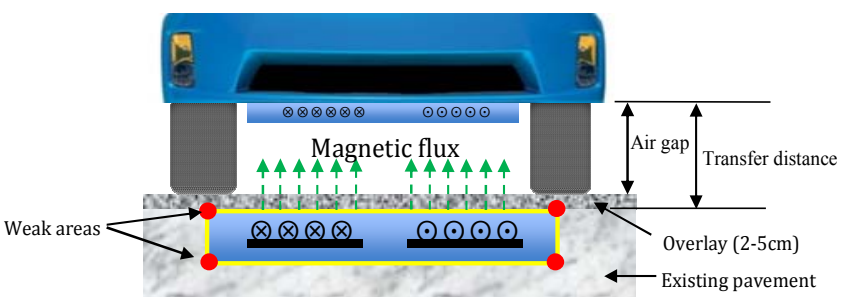

Fig. 3. Schematic of a potential E-Road structure

Solutions that may help improve the structural integrity can include: 1) Structural reinforcement by using high quality materials for both structural and overlay layers. This includes not only the selection of qualified raw materials, but also appropriate mixture design, production and construction processes. 2) Optimization by using different interface materials. In this, Joint systems can accommodate very large structural movements. For instance, polymer-modified asphaltic plug joints (APJ) can work within a temperature range from $-25{ }^{\circ} \mathrm{C}$ to $+45{ }^{\circ} \mathrm{C}$ and to sustain gap closings and openings from $-12.5 \mathrm{~mm}$ to $25 \mathrm{~mm}$, at the same time be able to take vertical gap movements up to a maximum of $5 \mathrm{~mm}$ [24]. Meanwhile, Interlayer systems have also been used a lot to control reflective cracking and preserve the integrity of the pavement. For instance, the Asphalt Rubber Membrane Interlayer (ARMI) can help reduce the stress concentrations while its structural thickness can reduce deflections and also 
moisture [25]. In addition, other interlayer systems such as geosynthetics and reinforcement interlayer (e.g., steel net) also have the potential to improve the structural integrity of the pavement. However, the real effectiveness for these solutions in E-Road structure is unknown and should be carefully investigated before implementation, or the failure in the form like reflective cracking, rutting and so on can be expected prematurely.

\section{B. Consideration over the long term maintenance}

Normally, the aim of pavement maintenance activities is to extend the road service lifetime and make users safe and feel comfortable. The maintenance for ordinary pavements usually includes two aspects: i) periodic maintenance activities to preserve the existing pavement conditions; ii) major rehabilitation activities including the resurfacing, restoration, rehabilitation and reconstruction [26]. In order to ensure the optimum functionality of E-Road for a very long time, the considerations regarding the maintenance management of the E-Road can be of great importance. However, this maintenance management will also be confronted with some practical challenges in reality, since the traditional guidance is hardly applicable. In this, due to the sensitivity of the IPT system to the energy transfer distance and spatial misalignments, the requirement for E-road surface quality could be much stricter than normal pavements. Hence, the periodic maintenance activities can be very important, in which the preventive maintenance technologies can be further focused. The preventive maintenance is carried out when the road is still in good condition to delay the potential surface failures, which includes activities like sealing the pavement surface and controlling the effects of oxidation, ravelling and surface cracking [27]. In addition, resurfacing of the overlay can be done every several years to ensure the protection of functionality, safety and comfort. Given the complex structure of E-Road and high initial cost, the major rehabilitation activities should be delayed as long as possible; even if inevitable in future, they are better to be limited to the road material sections rather than the whole structure. This can also be one of the reasons why the IPT facilities may be better envisaged to be prefabricated in the module and embedded as an entirety.

\section{Consideration over low electromagentic loss}

After embedment, one problem that is forgotten by most system developers is the potential electromagnetic loss that caused by the road surface material when magnetic fields pass through. This may further influence the IPT system's transfer efficiency. In fact, the wireless power transfer technologies have been explored a lot to recharge the batteries of embedded sensors, with the application in structural health monitoring of civil infrastructures like bridges and roadways [28-31]. In this, due to the electrical loss media like concrete, soil and moisture, the wireless energy transfer efficiency is considerably low, although it was found that improvement can be found by adapting the magnetic resonance technology. Similarly, energy loss can also be potentially induced by the E-Road that using IPT charging solution, since the power transfer medium will not be only the air but also the surrounding road surface materials. The authors in [32] employed an experimental test to assess this energy loss by an insertion of a $110 \mathrm{~mm}$ thickness concrete material (taken from the road) between the IPT charging transmitter and the receiver. The results suggest that the energy loss by the road surface materials (i.e. aged concrete in dry state) can be equivalently important with other resistive and ferrite core losses. In fact, this energy loss is closely related to the material's dielectric properties that can be characterized by the imaginary part of complex relative permittivity $\varepsilon_{\mathrm{r}}$. For instance, when microwaves propagate through a nonmagnetic medium, the power loss can be calculated through equation (1) (Sutton, 1989), which is decided by the $\varepsilon$ " of the lossy medium, together with the frequency and strength of the electric field.

$$
P_{\text {loss }}=2 \pi f \varepsilon_{0} \varepsilon^{\prime \prime}|E|^{2}
$$

Where, $\varepsilon^{\prime \prime}$ is the imaginary part of permittivity $\varepsilon_{\mathrm{r}} ; \mathrm{E}(\mathrm{V} / \mathrm{m})$ and $\mathrm{f}(\mathrm{Hz})$ are the magnitude and frequency of the internal oscillating electric fields; $\varepsilon_{0}$ is the vacuum permittivity, $8.854 * 10^{-12}(\mathrm{~F} / \mathrm{m})$.

A list of the relative permittivity of ordinary infrastructural materials is presented in TABLE I. , from which it can be seen that big differences exist among different materials' relative permittivity $\varepsilon_{\mathrm{r}}$ at the given frequency. In this sense, the road materials with smaller $\varepsilon_{\mathrm{r}}$ may cause less electromagnetic loss impact on the IPT system. However, the unknown permittivity of road materials (dry and wet) in IPT systems' working frequency range (normally below $200 \mathrm{kHz}$ ) makes it difficult to assess this energy loss quantitatively at the moment. A further study over the electromagnetic properties of road materials in IPT work frequency range and thus the potential influence to the IPT system is recommended, especially under extreme climatic conditions, e.g., rains and snows.

TABLE I. DIELECTRIC CONSTANT FOR DIFFERENT INFRASTRUCTURE MATERIALS AT 100 MHz (DANIELS, 2004, [33])

\begin{tabular}{|l|c|}
\hline Materials & $\boldsymbol{\varepsilon}_{\mathbf{r}}$ \\
\hline Air & 1 \\
\hline Water & 81 \\
\hline Snow & $6-12$ \\
\hline Ice & 4 \\
\hline Sand & $2-6$ (dry), 10-30 (wet) \\
\hline Clay & $2-6$ (dry), 5-40 (wet) \\
\hline Limestone & 7 (dry), 8 (wet) \\
\hline Granite & 5 (dry),7 (wet) \\
\hline Asphalt & $2-4$ (dry), 6-12 (wet) \\
\hline Concrete & $4-10$ (dry), 10-20 (wet) \\
\hline
\end{tabular}

\section{CONCLUSIONS}

From the road infrastructure perspective, this paper tried to further investigate the potential challenges that have not been taken into account for the success of on-the-road charging (or Electrified Road, E-Road) infrastructure. The survey on the IPT road charging pilots suggests that little research has been performed regarding the E-Road infrastructure's service performance in real life. In fact, the traditional construction and maintenance principles cannot be adopted directly, and severe modifications are needed. In this paper, specifically, the infrastructural materials that may potentially contribute to ERoad performance in aspects like structural integrity, cost- 
effective maintenance activities, and also smaller impact on the charging system were discussed. Last but not least, the authors hope that this paper can be useful for researchers and developers in this domain to be further aware of the impact of their choices and the needed cross-couplings between domains for the success of road electrification.

\section{ACKNOWLEDGEMENT}

This work was supported by the European Commission under FABRIC, a collaborative project part of the FP7 for research, technological development and demonstration. The authors would like to thank all partners within FABRIC for their cooperation and valuable contribution. Feng Chen gratefully acknowledges the support from Chinese Scholarship Council (CSC).

\section{REFERENCES}

[1] Siemens History. Elektromote. Available: http://www.siemens.com/history/en/innovations/transportation.htm\#toc$\underline{2}$.

[2] Les Brunton, “The trolleybus story,” IEE Review, Vol. 38, No. 2, 1992, pp. 57-61.

[3] Nelson Berman, “Roadway vehicle,” U.S. Patent No. 4129203, 1978.

[4] Jay D. Rynbrandt, “Electric car and roadway system,” U.S. Patent No. 4476947, 1984.

[5] Michael P. Hennessey and Max Donath, "Evaluation of the E-TRAN vehicle propulsion concept," Report No. MN/RC-94/03, University of Minnesota, 1994.

[6] Robert C. Post, "Urban mass transit- the life story of technology," Greenwood Press, Westport, London, 2007.

[7] Grant A, Covic. and John T. Boys, "Inductive Power Transfer," Proceedings of the IEEE, Vol. 101, No. 6, 2013, pp. 1276-1289.

[8] Systems Control Technology, Inc., "Roadway Powered Electric Vehicle Project Track Construction and Testing Program Phase," Research report UCB-ITS-PRR-94-07, California Partners for Advanced Transit and Highways (PATH), 1994.

[9] C. T. Rim, "The Development and Deployment of On-Line Electric Vehicles (OLEV)," available http://www.ecce2013.org/documents/2013\%20ECCE\%20Special\%20se ssions/SS3/SS3.2_WP_Chun.Rim.pdf.

[10] Flanders Drive, "Inductive Charging Applications for Electric Vehicles," available: http://www.flandersdrive.be/en/projects/inductivecharging .

[11] Swedish ICT Viktoria, "Slide-in Electric Road System-Inductive project report," available: https://www.viktoria.se/publications/Slide-in-ERSInductive-project-report .

[12] Robert L. Lytton, "Use of Geotextiles for Reinforcement and Strain Relief in Asphalt Concrete," Geotextiles and Geomembranes, Vol. 8, 1989, pp. 217-237.

[13] M.T. Mukhtar, B. J. Dempsey, "Interlayer Stress Absorbing Composite (ISAC) for Mitigating Reflection Cracking in Asphalt Concrete Overlays," Report No. UILU-ENG-96-2006, Illinois Department of Transportation, 1996.

[14] Hunter H. Wu, Aaron Gilchrist, Kylee D. Sealy, and Daniel Bronson, “ $A$ High Efficiency $5 \mathrm{~kW}$ Inductive Charger for EVs Using Dual Side Control," IEEE Transactions on Industrial Informatics, Vol. 8, No.3, 2012, pp: 585-595.

[15] Mickel Budhia, Grant A. Covic, John T. Boys, "Design and Optimization of Circular Magnetic Structures for Lumped Inductive Power Transfer Systems, " IEEE Transaction on Power Electronics, Vol. 26, No. 11, 2011, pp. 3096-3108.

[16] Mickel Budhia, Grant A. Covic, John T. Boys and Chang-Yu Huang, "Development and Evaluation of Single Sided Flux Couplers for
Contactless Electric Vehicle Charging," IEEE Energy Conversion Congress and Exposition (ECCE), 2011, pp. 614-621.

[17] Mickel Budhia, John T. Boys, Grant A. Covic, Chang-Yu Huang, "Development of a Single-Sided Flux Magnetic Coupler for Electric Vehicle IPT Charging Systems," IEEE Transactions on Industrial Electronics, 2013, pp. 318-328.

[18] Grant A. Covic, Michael L. G. Kissin, Dariusz Kacprzak, Niels Clausen, and Hao Hao, "A Bipolar Primary Pad Topology for EV Stationary Charging and Highway Power by Inductive Coupling," IEEE Energy Conversion Congress and Exposition (ECCE), 2011, pp. 1832-1838.

[19] J. G. Bolger, F. A. Kirsten, and L. S. Ng, "Inductive Power Coupling for an Electric Highway System," In 28th IEEE Vehicular Technology Conference, 1978, pp. 137-144.

[20] Sungwoo Lee, Jin Huh, Changbyung Park, Gyu-Hyeoung Cho, NamSup Choi, Chun-Taek Rim, "On-Line Electric Vehicle using Inductive Power Transfer System," IEEE Energy Conversion Congress and Exposition (ECCE), 2010, pp. 1598-1601.

[21] Jaegue Shin, Boyune Song, Seungyong Shin, Sanghoon Chung, Yangsu Kim, Goho Jung and Seongjeub Jeon, "Design of Buried Power Line for Roadway-Powered Electric Vehicle System," IEEE Wireless Power Transfer (WPT), 2013, pp. 56-57.

[22] Wei Zhang, Siu-Chung Wong, Chi K. Tse and Qianhong Chen, “A Study of Sectional Tracks in Roadway Inductive Power Transfer System," IEEE Energy Conversion Congress and Exposition (ECCE): Energy Conversion Innovation for a Clean Energy Future, 2011, pp. 822-826.

[23] Murat Yilmaz Veysel, T. Buyukdegirmenci, and Philip T. Krein, "General Design Requirements and Analysis of Roadbed Inductive Power Transfer System for Dynamic Electric Vehicle Charging,” IEEE Transportation Electrification Conference and Expo (ITEC), 2012, pp. 16.

[24] M.N. Partl, S. Hean, L. Poulikakos, "Asphaltic plug joint characterization and performance evaluation," in Proceedings of 9th international conference on asphalt pavements, ISAP, Copenhagen,2002.

[25] Flexible Pavement Design Manual. Florida Department of Transportation Pavement Management Office, 2008.

[26] AASHTO, "Guide for design of pavement structures," American Association of State Highway and Transportation Officials, Washington, DC, 1993.

[27] Ann M. Johnson, "Best Practices Handbook on Asphalt Pavement Maintenance," Report No. MN/RC-2000-04, University of Minnesota Center for Transportation Studies, 2000.

[28] Shan Jiang, "Optimum wireless power transmission for sensors embedded in concrete," Doctoral thesis, Florida International University, 2011.

[29] Khan M. Z. Shams, Mohammod Ali, “Wireless Power Transmission to a Buried Sensor in Concrete," IEEE Sensors Journal, Vol. 7, No. 12, 2007, pp. 1573-1577.

[30] Olutola Jonah, Stavros V. Georgakopoulos, "Wireless Power Transmission to Sensors Embedded in Concrete via Magnetic Resonance," 2011 IEEE International Symposium on Antennas and Propagation (APSURSI), 2011, pp. 1425-1428.

[31] Zhi Sun, Ian F. Akyildiz, "Magnetic Induction Communications for Wireless Underground Sensor Networks," IEEE Transactions on Antennas and Propagation, Vol. 58, No. 7, 2010, pp. 2426-2435.

[32] Omer C. Onar, John M. Miller, Steven L. Campbell, Chester Coomer, Cliff. P. White, and Larry E. Seiber, "A Novel Wireless Power Transfer for In-Motion EV/PHEV Charging," in Applied Power Electronics Conference and Exposition (APEC), 2013 Twenty-Eighth Annual IEEE, 2013, pp. 3073 - 3080.

[33] Daniels, David, “Ground Penetrating Radar (2nd Edition), chapter 4," The Institute of Electrical Engineers, London, UK, 2004. 